X.

\title{
A Cryogenic GaAs PHEMT/Ferroelectric Ku-Band Tunable Oscillator
}

Robert R. Romanofsky, Fred W. Van Keuls, and Felix A. Miranda

Lewis Research Center, Cleveland, Ohio

Prepared for the

3rd European Workshop on Low Temperature Electronics sponsored by the Dipartimento di Fisica, Universita' degli Sturh di Milan and IEEE Electron Devices Society

San Miniato, Tuscany, Italy, June 24-26, 1998

National Aeronautics and

Space Administration

Lewis Research Center 
Trade names or manufacturers' names are used in this report for identification only. This usage does not constitute an official endorsement, either expressed or implied, by the National Aeronautics and Space Administration.

Available from

NASA Center for Aerospace Information

800 Elkridge Landing Road

Linthicum Heights, MD 21090-2934

Price Code: A03
National Technical Information Service 5287 Port Royal Road Springfield, VA 22100

Price Code: A03 


\title{
A CRYOGENIC GaAs PHEMT/FERROELECTRIC Ku-BAND TUNABLE OSCILLATOR
}

\author{
Robert R. Romanofsky, Fred W. Van Keuls, ${ }^{1}$ Felix A. Miranda \\ National Aeronautics and Space Administration \\ Lewis Research Center \\ Cleveland, Ohio 44135 U.S.A.
}

\begin{abstract}
A Ku-band tunable oscillator operated at and below $77 \mathrm{~K}$ is described. The oscillator is based on two separate technologies: a $0.25 \mu \mathrm{m}$ GaAs pseudomorphic high electron mobility transistor (PHEMT) circuit optimized for cryogenic operation, and a gold microstrip ring resonator pattemed on a thin ferroelectric $\left(\mathrm{SrTiO}_{3}\right)$ film which was laser ablated onto a $\mathrm{LaAlO}_{3}$ substrate. A tuning range of up to $3 \%$ of the center frequency was achieved by applying dc bias between the ring resonator and ground plane. To the best of our knowledge, this is the first tunable oscillator based on a thin film ferroelectric structure demonstrated in the microwave frequency range. The design methodology of the oscillator and the performance characteristics of the tunable resonator are described.
\end{abstract}

\section{INTRODUCTION}

A key performance parameter of modern digital communication systems is phase noise, which can be regarded as short term signal instability. Phase noise is introduced into a system primarily by the local oscillator (LO) used in the receiver. The state-of-the-art in phase noise performance is represented by crystal sources which are multiplied up to the desired signal frequency. Since phase noise scales as $\mathbf{n}^{2}$, where $\mathrm{n}$ is the multiplication factor, crystal stabilized LOs are generally restricted to frequencies below several $\mathrm{GHz}$. Dielectric resonator oscillators (DROs) are commercially available up to at least $20 \mathrm{GHz}$. However, DROs do not lend themselves to electronic tuning or frequency locking. Further, the DRO resonator fabrication must be done independently of the oscillator circuit and its three-dimensional geometry impedes the fast, high volume production of the optimized circuit. Similarly, cavity stabilized oscillators offer excellent performance characteristics but are bulky and expensive. There is also rapidly growing interest in voltage controlled oscillators (VCOs) at Ku-band and higher frequencies [1-3]. The purpose of this work is to explore an entirely new VCO concept involving several different technologies. It has been shown experimentally that the use of a superconducting resonator, instead of gold, can improve phase noise by as much as $20 \mathrm{~dB}$ at X-band because of lower surface resistance [4]. Nevertheless, knowledge of the behavior of solid state devices for microwave applications at cryogenic temperatures, especially down-converters, is incomplete. The implications of phenomenon such as I/V collapse, carrier freeze-out, $1 / \mathrm{f}$ noise, etc. are still being studied $[5,6]$. This paper reports on the design and performance of a prototype cryogenic ferroelectric/PHEMT oscillator using a metallic rather than a superconducting resonator at this time.

'National Research Council—NASA Research Associate at Lewis Research Center. 


\section{TUNABLE RING RESONATOR}

A ring resonator fabricated from a multilayer structure comprised of an evaporated Au film with nominal thickness of $2 \mu \mathrm{m}$, an evaporated $15 \mathrm{~nm}$ thick titanium adhesion layer, and a $2 \mu \mathrm{m}$ $\mathrm{SrTiO}_{3}$ film deposited by laser ablation onto a (100) $\mathrm{LaAlO}_{3}$ substrate $(254 \mu \mathrm{m}$ thick), is used as the stabilizing element in the VCO. A standard lift-off etching process was used to pattern the circuit. The ring resonator, which is three guide wavelengths in circumference at the primary operating frequency, is shown in the left half of Fig. 1. The characteristic impedance of the microstrip ring was $25 \Omega$. This impedance was carefully chosen and nearly optimal in the sense of providing minimum conductor loss (to improve $\mathrm{Q}$ ) while avoiding higher order mode problems. The ratio of microstrip width to mean radius of the ring was 0.24 , and the dominant (quasiTEM) mode was $\mathrm{TM}_{310}$ (no azimuthal magnetic field component) [7]. The estimated maximum unloaded $Q$ was about 500 compared to less than 200 for a $50 \Omega$ ring. These values compare

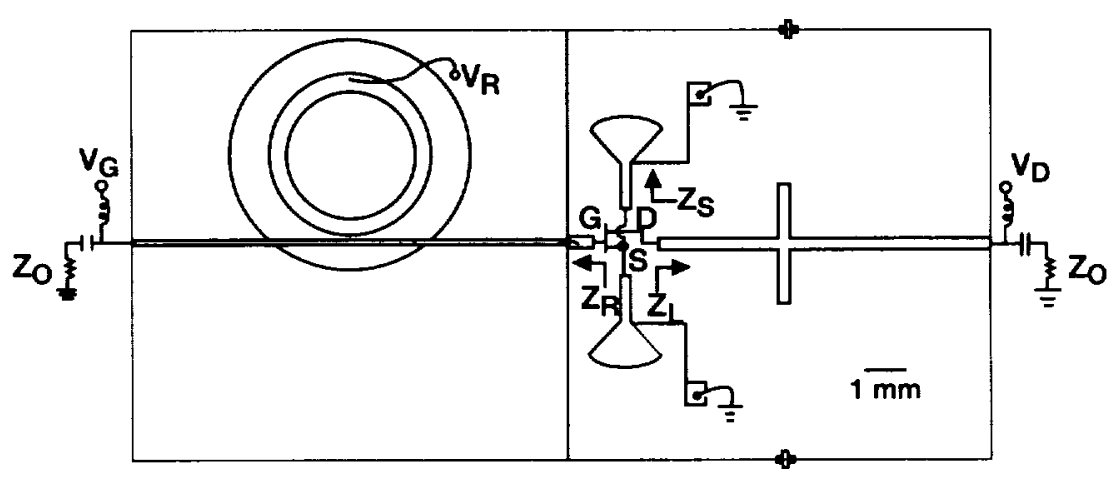

Figure 1.-Layout of the complete VCO.

favorably to conventional varactor-loaded rings [8]. For comparison, the resonator used in [5], which was kept at room temperature but coupled to a cryogenic PHEMT, had a loaded Q of 160. The outer circle represents the location of the $\mathrm{SrTiO}_{3}$ after selective etching with $7 \%$ hydrofluoric acid. The ring is tuned by applying a dc electric field to the $\mathrm{SrTiO}_{3}$ film. Bias is applied via a $25 \mu \mathrm{m}$ diameter $\mathrm{Au}$ wire bonded by thermal-compression near the 12:00 position on the ring (i.e. a virtual short circuit position). It has been shown that the dielectric constant $\left(\varepsilon_{\mathrm{r}}\right)$ of the $\mathrm{SrTiO}_{3}$ film varies nonlinearly from 300 at $295 \mathrm{~K}$ to as much as 5000 below $77 \mathrm{~K}$ [9]. At cryogenic temperatures $\varepsilon_{\mathrm{r}}$ can be made to approach the room temperature value with the dc bias. That is, tuning to lower (higher) resonant frequencies is achieved by decreasing (increasing) the magnitude of the dc bias applied to the ring. Frequency shifts of $12 \%$ at $16 \mathrm{GHz}$ have been measured at $77 \mathrm{~K}$ with a bias of $450 \mathrm{~V}$ [10]. Figure 2 shows the magnitude of the insertion loss as a function of bias. The resonator was characterized using the test fixture and techniques described in the next section. The measurements are referred to the edge (input) of the $1 \mathrm{~cm}$ long circuit. Note that the sharp resonances are maintained by controlling the potential of the microstrip line as well as the ring, relative to the back plane at dc ground. That is, the coupling coefficient of the side coupled resonator can be controlled as well as the resonant frequency in order to operate at an optimal point or "sweet spot." Resonance splitting, which often plagues side-coupled resonators, was not a problem [11]. 


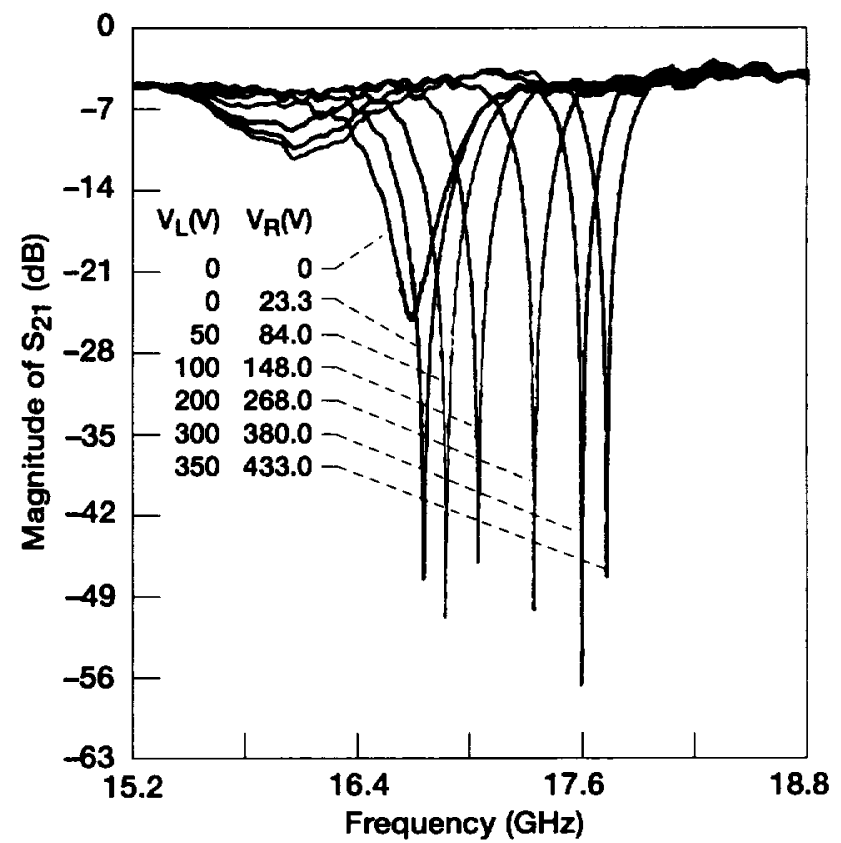

Figure 2. $-\left|\mathrm{S}_{21}\right|$ of the side-coupled $\mathrm{Au} / \mathrm{SrTiO}_{3} / \mathrm{LaAlO}_{3}$ resonator as a function of bias. The voltages correspond to the dc bias on the ring $\left(N_{R}\right)$ and microstrip line $N_{\mathbf{D}}$.

\section{PSEUDOMORPHIC HEMT CHARACTERIZATION}

An Avantek/HP $0.25 \mu \mathrm{m}$ gate length ATF-35076 PHEMT, housed in a ceramic microstrip package, was chosen as the active device because of its premium noise figure and associated gain and low cost. For the purpose of obtaining the scattering (S-) parameters of the PHEMT, the device was attached to a $0.5 \mathrm{~mm}$ thick alumina $\left(\mathrm{Al}_{2} \mathrm{O}_{3}\right)$ coplanar waveguide carrier, which was inserted into a modified Design Techniques ${ }^{\circledR}$ fixture. The fixture was connected to a HP $8510 \mathrm{C}$ vector network analyzer with semi-rigid coaxial cables. A room temperature calibration using "short, open, and through" standards first established reference planes a few $\mathrm{mm}$ from the carrier center. Reference planes were then shifted to the device ports using an offset short and dialing in an appropriate port extension with the $8510 \mathrm{C}$. The fixture, carrier, and PHEMT were cooled to $77 \mathrm{~K}$ using liquid nitrogen. The magnitude of $S_{21}, S_{11}$ and $S_{22}$ are shown in figure 3 for a drain $\left(V_{d}\right)$ and gate $\left(\mathrm{V}_{g}\right)$ voltage of 2.1 and $-0.2 \mathrm{~V}$, respectively. The corresponding drain current $\left(\mathrm{I}_{\mathrm{d}}\right)$ was about $13 \mathrm{~mA}$. A design frequency of $16.7 \mathrm{GHz}$ was chosen so as to fall within the performance range of the ring resonator (see Fig. 2). The S-parameter magnitudes and phase angles were: $\mathrm{S}_{11}$ $=0.462,141.0^{\circ}, \mathrm{S}_{12}=0.067,-105.0^{\circ}, \mathrm{S}_{21}=2.28,-81.4^{\circ}, \mathrm{S}_{22}=0.22,107.5^{\circ}$. Several devices were measured in this way on different occasions with consistent results. 

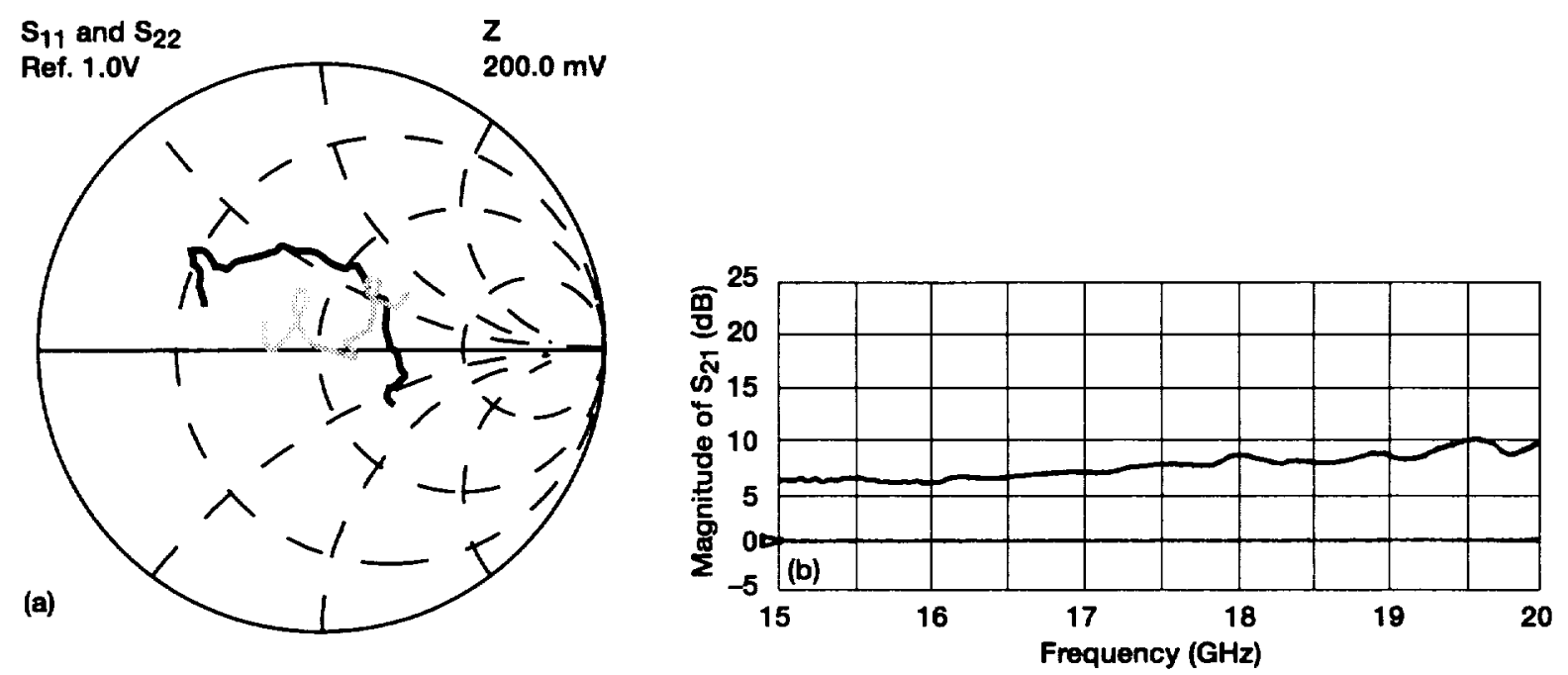

Figure 3.- (a) Smith chart showing $S_{11}$ (bold) and $S_{22}$ (light) and (b) log-magnitude plot showing $\left|S_{21}\right|$ of the PHEMT, all at $77 \mathrm{~K}$. $\mathrm{V}_{\mathrm{d}}=2.1 \mathrm{~V}, \mathrm{~V}_{\mathrm{g}}=-0.2 \mathrm{~V}$, and $\mathrm{I}_{\mathrm{d}}=13 \mathrm{~mA}$.

\section{VOLTAGE CONTROLLED OSCILLATOR DESIGN}

The PHEMT portion of the VCO was constructed on $0.25 \mathrm{~mm}$ thick $\mathrm{Al}_{2} \mathrm{O}_{3}$ and is shown in the right half of Fig. 1. The circuit pattern was defined using a standard additive, as opposed to etchback, Au electroplating process. The PHEMT leads were carefully trimmed so that it fit snugly into the region indicated. Since the PHEMT was unconditionally stable as tested, an inductance was inserted between the source and ground. An iterative computer routine was used to vary the source impedance $\left(Z_{S}\right)$ to maximize the negative resistance of the PHEMT while preserving enough loop gain. Specifically, with a $Z_{S}$ of $j 35 \Omega$, the new $S$-parameters became: $S_{11}=1.59$, $94.3^{\circ}, \mathrm{S}_{12}=0.626,3.7^{\circ}, \mathrm{S}_{22}=1.223,92.4^{\circ}, \mathrm{S}_{21}=2.197,-135.8^{\circ}$. The resulting stability factor (K) was -0.499 and the magnitude of $\left(\mathrm{S}_{11} \mathrm{~S}_{22}-\mathrm{S}_{12} \mathrm{~S}_{21}\right)=1.284$. The source inductance was realized by inserting a section of $50 \Omega$ microstrip $1.08 \mathrm{~mm}$ long at each source connection. The normalized impedance $\left(Z_{R}\right)$ of the ring circuit at the design frequency was 0.639-j0.228 $\Omega$, which includes the effects of the $5 \mathrm{~mm}$ section of microstrip intervening between the gate terminal and the bisector of the ring. This impedance corresponds to the second resonance from the left in Fig. 2. The bias on the ring was $23 \mathrm{~V}$ and the bias on the microstrip was $0 \mathrm{~V}$. With this biasing scheme there was no need to be concerned with floating the PHEMT voltages with respect to ground since the gate and ring circuit could be directly dc coupled. With the ring resonator circuit connected to the gate of the PHEMT as shown in Fig. 1, the impedance looking into the drain was $-24.9+j 47.7$ or $\Gamma=1.6$. The drain matching circuit shown in Fig. 1 provided a $\mathrm{Z}_{\mathrm{L}}=$ $8.3-\mathrm{j} 47.7$ as is customarily done to ensure oscillation [12]. The VCO operates below $77 \mathrm{~K}$, near the dielectric constant maximum of the $\mathrm{SrTiO}_{3}$, where the noise figure of the PHEMT and the surface resistance of the Au resonator are minimized. A particular operating temperature of $43 \mathrm{~K}$ was chosen to provide the maximum field induced tunability of the $\mathrm{SrTiO}_{3}$. For testing purposes, both circuits were attached to a brass fixture with conductive epoxy. The fixture was inserted into the vacuum can of a closed-cycle He gas refrigerator equipped with semi-rigid coaxial cables. 


\section{RESULTS AND CONCLUSIONS}

Changing the bias on the ring from 0 to $38 \mathrm{~V}$ varied the oscillator frequency by about $100 \mathrm{MHz}$ around the center frequency. Figure 4(a) shows the spectrum of the oscillator over a very broad bandwidth. No spurs or sub-harmonics were observed. Figure 4(b) shows a typical signal for the $\mathrm{LO}$ at a ring voltage of $38 \mathrm{~V}$. By increasing the ring voltage to $250 \mathrm{~V}$, the tuning range was extended over $500 \mathrm{MHz}$.

In conclusion, a novel tunable microwave ring resonator at $16.7 \mathrm{GHz}$ has been developed. It offers potential advantages over traditional varactor-loaded rings and DROs. To the best of our knowledge, this is the first time that a tunable oscillator based on a thin film ferroelectric structure has been demonstrated at such a high frequency. A successful design approach for such a cryogenic oscillator has been developed. In the near future, the Au ring will be replaced with a $\mathrm{YBa}_{2} \mathrm{Cu}_{3} \mathrm{O}_{7-\delta}$ ring and phase noise measurements will be made to compare performance. The merits of this VCO reside in its high performance potential, small size, simplicity of implementation, MMIC compatibility and its potential for low cost, high volume production.
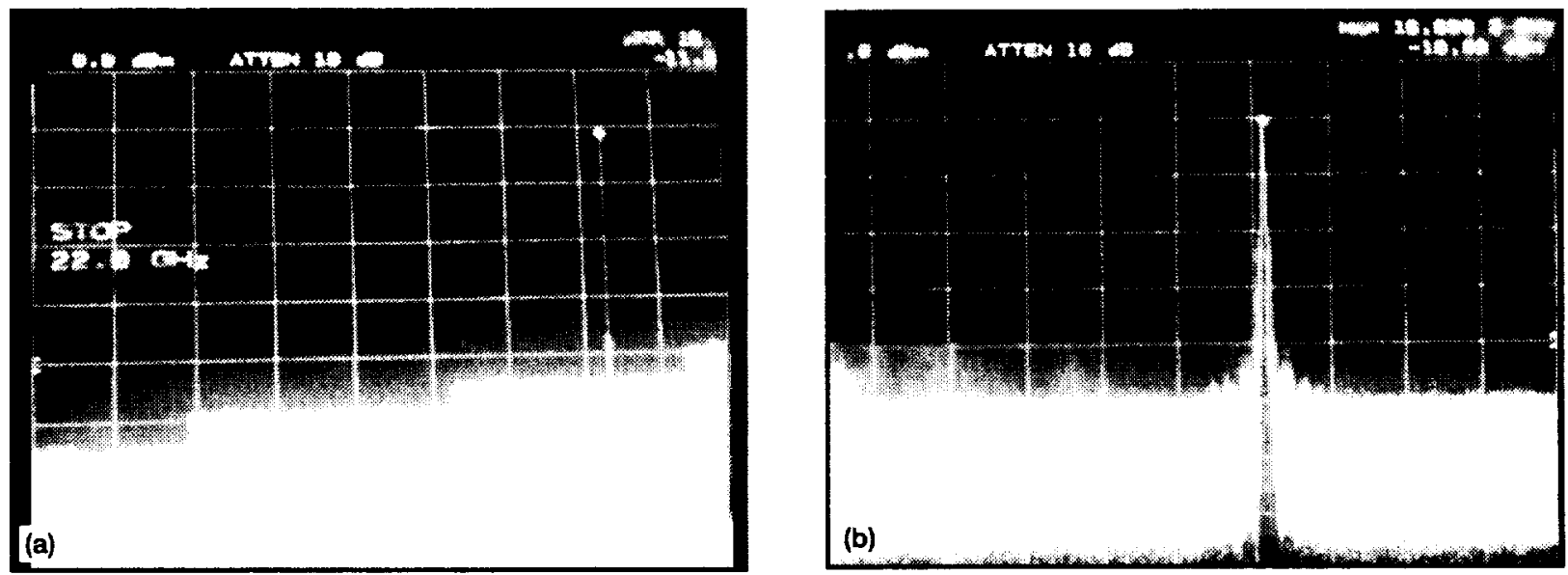

Figure 4. - VCO signals as measured on an HP $8566 \mathrm{~B}$ Spectrum Analyzer at $43 \mathrm{~K}$ with $\mathrm{V}_{d}=2.1 \mathrm{~V}, \mathrm{~V}_{\mathrm{g}}=-0.2 \mathrm{~V}, \mathrm{I}_{\mathrm{d}}=13.9 \mathrm{~mA}$ and Vring $=38 \mathrm{~V}$. The scale on (a) is 2 to $22 \mathrm{GHz}$, and (b) shows a $500 \mathrm{MHz}$ span with oscillation frequency at $16.696 \mathrm{MHz}$.

\section{References}

[1] J. Portilla, M. de la Fuente, J. Pascual, and E. Artal, IEEE Microwave \& Guided Wave Let., Vol. 7 (1997) pp. 380-382.

[2] K. Kobayashi, L. Tran, A. Oki, et al., IEEE Microwave \& Guided Wave Let., Vol. 5 (1995) pp. 311-312.

[3] J. Lin, Y. Chen, D. Humphrey, et al., IEEE Microwave \& Guided Wave Let., Vol. 5 (1995) pp. $379-381$.

[4] A. Khanna, M. Schmidt, and R. Hammond, Microwave Journal, Vol. 34 (1991) pp. 127-130.

[5] O. Llopis, R. Plana, H. Amine, et al., IEEE Trans. Microwave Theory Tech., Vol. 41 (1993) pp. $369-374$.

[6] R. Romanofsky, IEEE Microwave \& Guided Wave Let., Vol. 6 (1996) pp. 286-288.

[7] Y. Wu and F. Rosenbaum, IEEE Trans. Microwave Theory Tech., Vol. 21 (1973) pp. 487-489.

[8] K. Chang, S. Martin, F. Wang, and J. Klein, IEEE Trans. Microwave Theory Tech., Vol. 35 (1987) pp. $1288-1295$.

[9] M.J. Dalberth, R.E. Stauber, J.C. Price, C.T. Rogers, and D. Galt, Appl. Phys. Lett., Vol. 72, (1998), pp. 507-509.

[10] F. Van Keuls, R. Romanofsky, D. Bohman, and F. Miranda, "Influence of the Biasing Scheme on the Performance of $\mathrm{Au} / \mathrm{SrTiO}_{3} / \mathrm{LaAlO}_{3}$ Thin Film Conductor/Ferroelectric Tunable Ring Resonators", Presented at the $10^{\text {th }}$ Int'l Symp. Integrated Ferroelectrics, Monterey, CA, Mar. 1-4, 1998.

[11] S. Lu and A. Ferendeci, Electronics. Let., Vol. 30 (1994) pp. 1314-1315.

[12] G. Vendelin, Design of Amplifiers and Oscillators by the S-Parameter Method (John Wiley \& Sons, New York, 1982) pp. 132-182. 
Public reporting burden for this collection of information is estimated to average 1 hour per response, including the time for reviewing instructions, searching existing data sources, gathering and maintaining the data needed, and completing and reviewing the collection of information. Send comments regarding this bunden estimate or any other aspect of this collection of information, including suggestions for reducing this burden, to Washington Headquarters Services, Directorate for Information Operations and Reports, 1215 Jelfe
Davis Highway, Suite 1204. Aftington, VA 22202-4302, and to the Office of Management and Budget, Paperwork Reduction Project (0704-0188), Washington, DC 20503.

\begin{tabular}{|l|c|c}
\hline 1. AGENCY USE ONLY (Leave blank) & $\begin{array}{c}\text { 2. REPORT DATE } \\
\text { April } 1998\end{array}$ & $\begin{array}{r}\text { 3. REPORT TYPE AND DATES COVERED } \\
\text { Technical Memorandum }\end{array}$
\end{tabular}

\section{TITLE AND SUBTTTLE}

A Cryogenic GaAs PHEMT/Ferroelectric Ku-Band Tunable Oscillator

\section{AUTHOR(S)}

Robert R. Romanofsky, Fred W. Van Keuls, and Felix A. Miranda

\section{PERFORMING ORGANIZATION NAME(S) AND ADDRESS(ES)}

National Aeronautics and Space Administration

Lewis Research Center

Cleveland, Ohio 44135-3191

\section{SPONSORINGMONITORING AGENCY NAME(S) AND ADDRESS(ES)}

National Aeronautics and Space Administration

Washington, DC 20546-0001

\section{FUNDING NUMBERS}

WU-632-50-5D-00

PERForming ORGanization REPORT NUMBER

E-11113

10. SPONSORINGMONITORING AGENCY REPORT NUMBER

NASA TM-1998-206967

11. SUPPLEMENTARY NOTES

Prepared for the 3rd European Workshop on Low Temperature Electronics sponsored by the Dipartimento di Fisica, Universita' degli Sturh di Milan and IEEE Electron Devices Society, San Miniato, Tuscany, Italy, June 24-26, 1998. Robert R. Romanofsky and Felix A. Miranda, NASA Lewis Research Center; Fred W. Van Keuls, National Research Council-NASA Research Associate at Lewis Research Center. Responsible person, Robert R. Romanofsky, organization code 5640, (216) 433-3507.

\begin{tabular}{l|l} 
12a. DISTRIBUTION/AVAILABILITY STATEMENT & 12b. DISTRIBUTION CODE
\end{tabular}

Unclassified - Unlimited

Subject Categories: 00 and 00

Distribution: Nonstandard

This publication is available from the NASA Center for AeroSpace Information, (301) $621-0390$.

13. ABSTRACT (Maximum 200 words)

A Ku-band tunable oscillator operated at and below $77 \mathrm{~K}$ is described. The oscillator is based on two separate technologies: a $0.25 \mathrm{~mm}$ GaAs pseudomorphic high electron mobility transistor (PHEMT) circuit optimized for cryogenic operation, and a gold microstrip ring resonator patterned on a thin ferroelectric $\left(\mathrm{SrTiO}_{3}\right)$ film which was laser ablated onto a $\mathrm{LaAlO}_{3}$ substrate. A tuning range of up to $3 \%$ of the center frequency was achieved by applying dc bias between the ring resonator and ground plane. To the best of our knowledge, this is the first tunable oscillator based on a thin film ferroelectric structure demonstrated in the microwave frequency range. The design methodology of the oscillator and the performance characteristics of the tunable resonator are described.

14. SUBJECT TERMS

Resonators; Microwave oscillators; Voltage controlled oscillator

15. NUMBER OF PAGES 11

16. PRICE CODE

A03

\begin{tabular}{|c|c|c|}
\hline $\begin{array}{c}\text { 17. SECURTY CLASSIFICATION } \\
\text { OF REPORT } \\
\text { Unclassified }\end{array}$ & $\begin{array}{c}\text { 18. SECURTY CLASSIFICATION } \\
\text { OF THIS PAGE } \\
\text { Unclassified }\end{array}$ & $\begin{array}{c}\text { 19. SECURITY CLASSIFICATION } \\
\text { OF ABSTRACT } \\
\text { Unclassified }\end{array}$ \\
\hline
\end{tabular}

NSN 7540-01-280-5500

\section{LIMITATION OF ABSTRACT}


NASA/TM-1998-206967

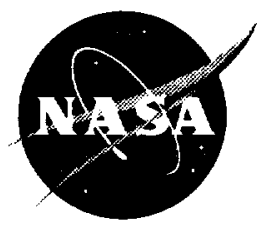

\section{A Cryogenic GaAs PHEMT/Ferroelectric $\mathrm{Ku}$-Band Tunable Oscillator}

Robert R. Romanofsky, Fred W. Van Keuls, and Felix A. Miranda

Lewis Research Center, Cleveland, Ohio

Prepared for the

3rd European Workshop on Low Temperature Electronics sponsored by the Dipartimento di Fisica, Universita' degli Sturh di Milan and IEEE Electron Devices Society

San Miniato, Tuscany, Italy, June 24-26, 1998

National Aeronautics and

Space Administration

Lewis Research Center 
Trade names or manufacturers' names are used in this report for identification only. This usage does not constitute an official endorsement, either expressed or implied, by the National Aeronautics and Space Administration.

Available from

NASA Center for Aerospace Information

800 Elkridge Landing Road

Linthicum Heights, MD 21090-2934

Price Code: A03
National Technical Information Service 5287 Port Royal Road Springfield, VA 22100

Price Code: A03 


\title{
A CRYOGENIC GaAs PHEMT/FERROELECTRIC Ku-BAND TUNABLE OSCILLATOR
}

\author{
Robert R. Romanofsky, Fred W. Van Keuls, ${ }^{1}$ Felix A. Miranda \\ National Aeronautics and Space Administration \\ Lewis Research Center \\ Cleveland, Ohio 44135 U.S.A.
}

\begin{abstract}
A Ku-band tunable oscillator operated at and below $77 \mathrm{~K}$ is described. The oscillator is based on two separate technologies: a $0.25 \mu \mathrm{m}$ GaAs pseudomorphic high electron mobility transistor (PHEMT) circuit optimized for cryogenic operation, and a gold microstrip ring resonator patterned on a thin ferroelectric $\left(\mathrm{SrTiO}_{3}\right)$ film which was laser ablated onto a $\mathrm{LaAlO}_{3}$ substrate. A tuning range of up to $3 \%$ of the center frequency was achieved by applying dc bias between the ring resonator and ground plane. To the best of our knowledge, this is the first tunable oscillator based on a thin film ferroelectric structure demonstrated in the microwave frequency range. The design methodology of the oscillator and the performance characteristics of the tunable resonator are described.
\end{abstract}

\section{INTRODUCTION}

A key performance parameter of modern digital communication systems is phase noise, which can be regarded as short term signal instability. Phase noise is introduced into a system primarily by the local oscillator (LO) used in the receiver. The state-of-the-art in phase noise performance is represented by crystal sources which are multiplied up to the desired signal frequency. Since phase noise scales as $\mathbf{n}^{2}$, where $\mathbf{n}$ is the multiplication factor, crystal stabilized LOs are generally restricted to frequencies below several GHz. Dielectric resonator oscillators (DROs) are commercially available up to at least $20 \mathrm{GHz}$. However, DROs do not lend themselves to electronic tuning or frequency locking. Further, the DRO resonator fabrication must be done independently of the oscillator circuit and its three-dimensional geometry impedes the fast, high volume production of the optimized circuit. Similarly, cavity stabilized oscillators offer excellent performance characteristics but are bulky and expensive. There is also rapidly growing interest in voltage controlled oscillators (VCOs) at Ku-band and higher frequencies [1-3]. The purpose of this work is to explore an entirely new VCO concept involving several different technologies. It has been shown experimentally that the use of a superconducting resonator, instead of gold, can improve phase noise by as much as $20 \mathrm{~dB}$ at X-band because of lower surface resistance [4]. Nevertheless, knowledge of the behavior of solid state devices for microwave applications at cryogenic temperatures, especially down-converters, is incomplete. The implications of phenomenon such as $I / V$ collapse, carrier freeze-out, $1 /$ f noise, etc. are still being studied $[5,6]$. This paper reports on the design and performance of a prototype cryogenic ferroelectric/PHEMT oscillator using a metallic rather than a superconducting resonator at this time.

${ }^{1}$ National Research Council-NASA Research Associate at Lewis Research Center. 


\section{TUNABLE RING RESONATOR}

A ring resonator fabricated from a multilayer structure comprised of an evaporated Au film with nominal thickness of $2 \mu \mathrm{m}$, an evaporated $15 \mathrm{~nm}$ thick titanium adhesion layer, and a $2 \mu \mathrm{m}$ $\mathrm{SrTiO}_{3}$ film deposited by laser ablation onto a (100) $\mathrm{LaAlO}_{3}$ substrate $(254 \mu \mathrm{m}$ thick), is used as the stabilizing element in the VCO. A standard lift-off etching process was used to pattern the circuit. The ring resonator, which is three guide wavelengths in circumference at the primary operating frequency, is shown in the left half of Fig. 1. The characteristic impedance of the microstrip ring was $25 \Omega$. This impedance was carefully chosen and nearly optimal in the sense of providing minimum conductor loss (to improve $Q$ ) while avoiding higher order mode problems. The ratio of microstrip width to mean radius of the ring was 0.24 , and the dominant (quasiTEM) mode was $\mathrm{TM}_{310}$ (no azimuthal magnetic field component) [7]. The estimated maximum unloaded $Q$ was about 500 compared to less than 200 for a $50 \Omega$ ring. These values compare

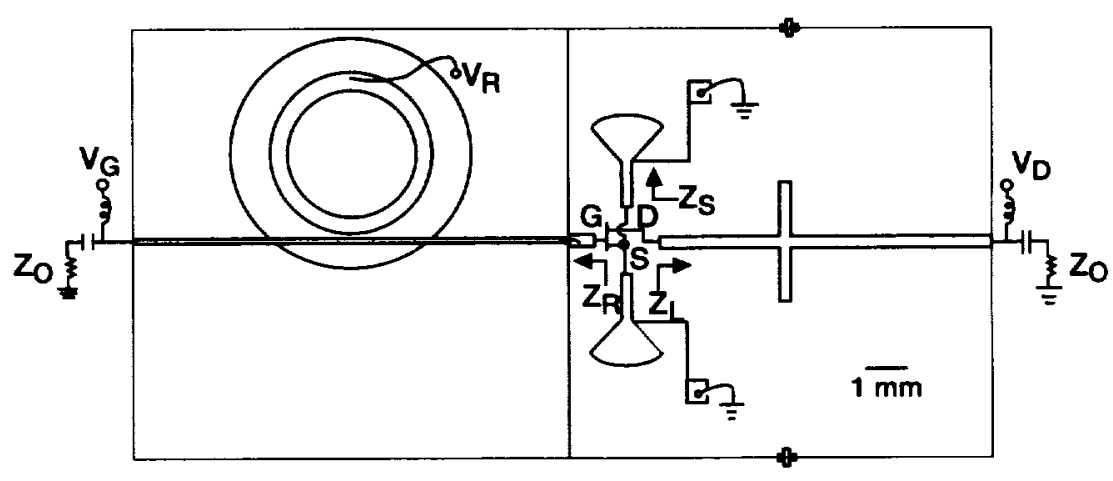

Figure 1.-Layout of the complete VCO.

favorably to conventional varactor-loaded rings [8]. For comparison, the resonator used in [5], which was kept at room temperature but coupled to a cryogenic PHEMT, had a loaded Q of 160. The outer circle represents the location of the $\mathrm{SrTiO}_{3}$ after selective etching with $7 \%$ hydrofluoric acid. The ring is tuned by applying a dc electric field to the $\mathrm{SrTiO}_{3}$ film. Bias is applied via a $25 \mu \mathrm{m}$ diameter $\mathrm{Au}$ wire bonded by thermal-compression near the 12:00 position on the ring (i.e. a virtual short circuit position). It has been shown that the dielectric constant $\left(\varepsilon_{\mathrm{r}}\right)$ of the $\mathrm{SrTiO}_{3}$ film varies nonlinearly from 300 at $295 \mathrm{~K}$ to as much as 5000 below $77 \mathrm{~K}$ [9]. At cryogenic temperatures $\varepsilon_{\mathrm{r}}$ can be made to approach the room temperature value with the dc bias. That is, tuning to lower (higher) resonant frequencies is achieved by decreasing (increasing) the magnitude of the dc bias applied to the ring. Frequency shifts of $12 \%$ at $16 \mathrm{GHz}$ have been measured at $77 \mathrm{~K}$ with a bias of $450 \mathrm{~V}$ [10]. Figure 2 shows the magnitude of the insertion loss as a function of bias. The resonator was characterized using the test fixture and techniques described in the next section. The measurements are referred to the edge (input) of the $1 \mathrm{~cm}$ long circuit. Note that the sharp resonances are maintained by controlling the potential of the microstrip line as well as the ring, relative to the back plane at dc ground. That is, the coupling coefficient of the side coupled resonator can be controlled as well as the resonant frequency in order to operate at an optimal point or "sweet spot." Resonance splitting, which often plagues side-coupled resonators, was not a problem [11]. 


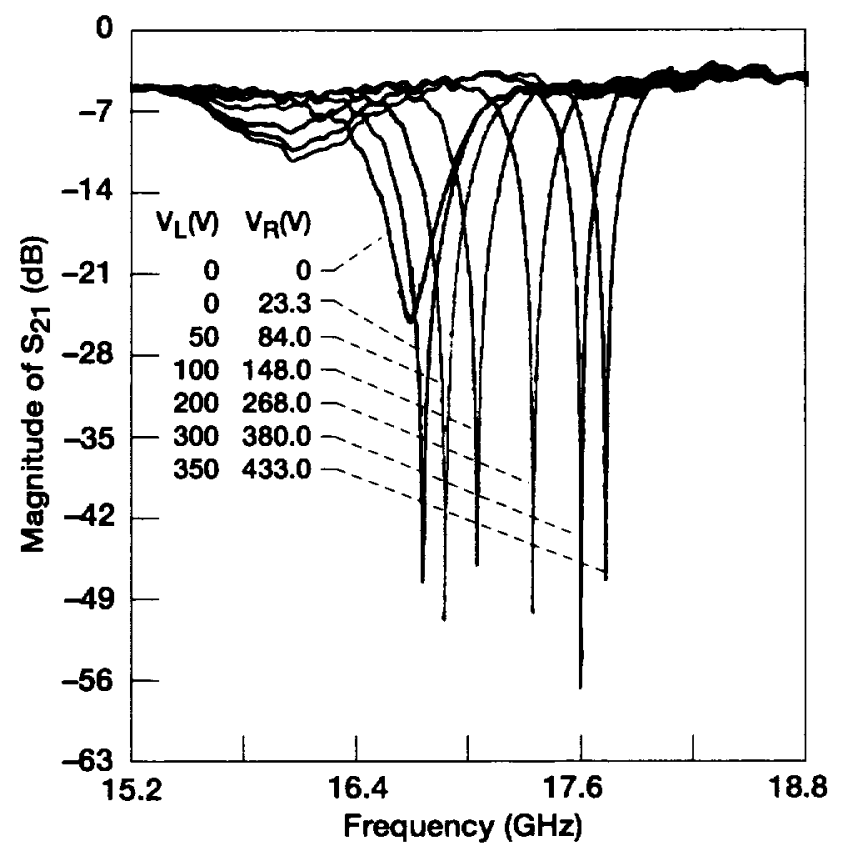

Figure 2.- $\left|\mathrm{S}_{21}\right|$ of the side-coupled $\mathrm{Au} / \mathrm{SrTiO}_{3} / \mathrm{LaAlO}_{3}$ resonator as a function of bias. The voltages correspond to the dc bias on the ring $\left.N_{R}\right)$ and microstrip line $\mathrm{N}_{\mathrm{U}}$.

\section{PSEUDOMORPHIC HEMT CHARACTERIZATION}

An Avantek/HP $0.25 \mu \mathrm{m}$ gate length ATF-35076 PHEMT, housed in a ceramic microstrip package, was chosen as the active device because of its premium noise figure and associated gain and low cost. For the purpose of obtaining the scattering (S-) parameters of the PHEMT, the device was attached to a $0.5 \mathrm{~mm}$ thick alumina $\left(\mathrm{Al}_{2} \mathrm{O}_{3}\right)$ coplanar waveguide carrier, which was inserted into a modified Design Techniques ${ }^{\circledR}$ fixture. The fixture was connected to a HP $8510 \mathrm{C}$ vector network analyzer with semi-rigid coaxial cables. A room temperature calibration using "short, open, and through" standards first established reference planes a few mm from the carrier center. Reference planes were then shifted to the device ports using an offset short and dialing in an appropriate port extension with the 8510C. The fixture, carrier, and PHEMT were cooled to $77 \mathrm{~K}$ using liquid nitrogen. The magnitude of $\mathrm{S}_{21}, \mathrm{~S}_{11}$ and $\mathrm{S}_{22}$ are shown in figure 3 for a drain $\left(\mathrm{V}_{\mathrm{d}}\right)$ and gate $\left(V_{g}\right)$ voltage of 2.1 and $-0.2 \mathrm{~V}$, respectively. The corresponding drain current $\left(I_{d}\right)$ was about $13 \mathrm{~mA}$. A design frequency of $16.7 \mathrm{GHz}$ was chosen so as to fall within the performance range of the ring resonator (see Fig. 2). The S-parameter magnitudes and phase angles were: $S_{11}$ $=0.462,141.0^{\circ}, S_{12}=0.067,-105.0^{\circ}, S_{21}=2.28,-81.4^{\circ}, S_{22}=0.22,107.5^{\circ}$. Several devices were measured in this way on different occasions with consistent results. 


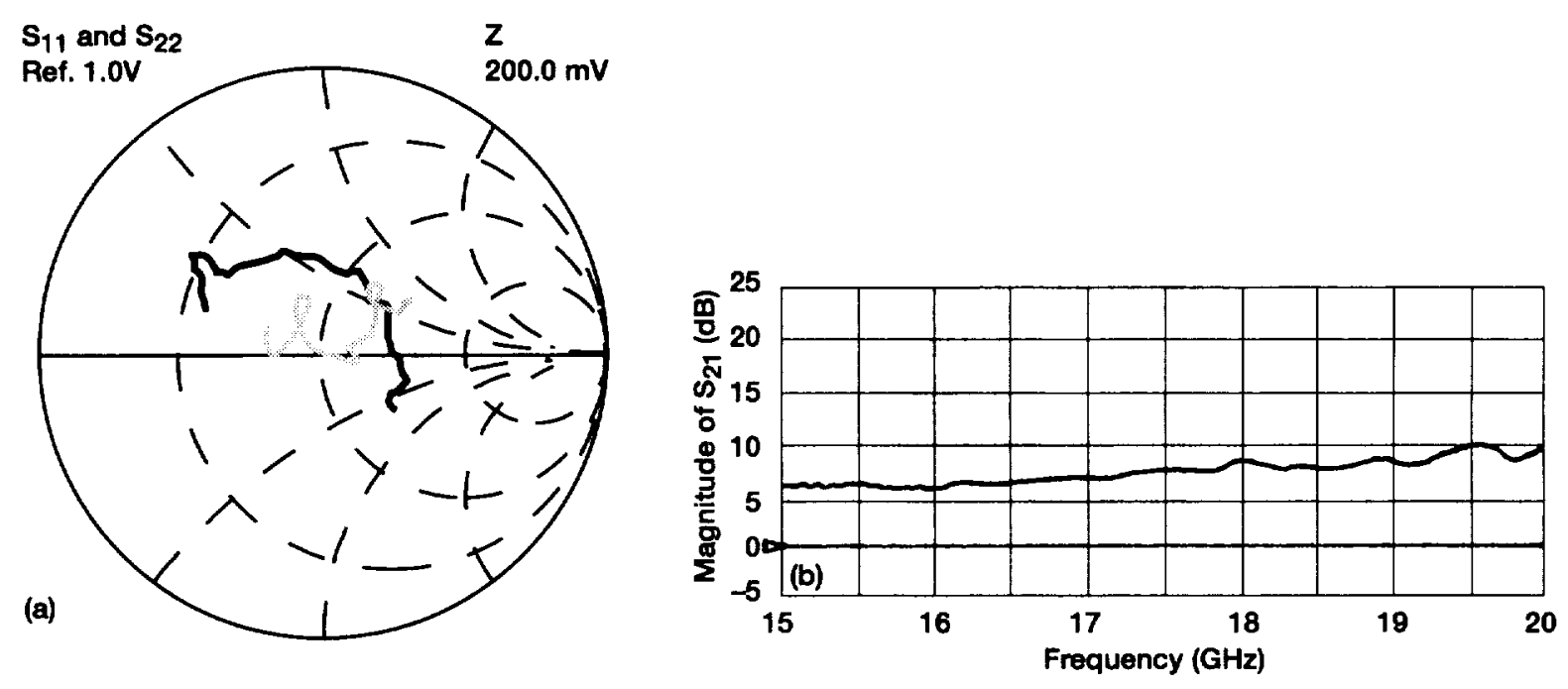

Figure 3.- (a) Smith chart showing $S_{11}$ (bold) and $S_{22}$ (light) and (b) log-magnitude plot showing $\left|S_{21}\right|$ of the PHEMT, all at $77 \mathrm{~K} . \mathrm{V}_{\mathrm{d}}=2.1 \mathrm{~V}, \mathrm{~V}_{\mathrm{g}}=-0.2 \mathrm{~V}$, and $\mathrm{I}_{d}=13 \mathrm{~mA}$.

\section{VOLTAGE CONTROLLED OSCILLATOR DESIGN}

The PHEMT portion of the VCO was constructed on $0.25 \mathrm{~mm}$ thick $\mathrm{Al}_{2} \mathrm{O}_{3}$ and is shown in the right half of Fig. 1. The circuit pattern was defined using a standard additive, as opposed to etchback, Au electroplating process. The PHEMT leads were carefully trimmed so that it fit snugly into the region indicated. Since the PHEMT was unconditionally stable as tested, an inductance was inserted between the source and ground. An iterative computer routine was used to vary the source impedance $\left(Z_{S}\right)$ to maximize the negative resistance of the PHEMT while preserving enough loop gain. Specifically, with a $Z_{S}$ of $j 35 \Omega$, the new $S$-parameters became: $S_{11}=1.59$, $94.3^{\circ}, \mathrm{S}_{12}=0.626,3.7^{\circ}, \mathrm{S}_{22}=1.223,92.4^{\circ}, \mathrm{S}_{21}=2.197,-135.8^{\circ}$. The resulting stability factor (K) was -0.499 and the magnitude of $\left(\mathrm{S}_{11} \mathrm{~S}_{22}-\mathrm{S}_{12} \mathrm{~S}_{21}\right)=1.284$. The source inductance was realized by inserting a section of $50 \Omega$ microstrip $1.08 \mathrm{~mm}$ long at each source connection. The normalized impedance $\left(\mathrm{Z}_{\mathrm{R}}\right)$ of the ring circuit at the design frequency was 0.639-j0.228 $\Omega$, which includes the effects of the $5 \mathrm{~mm}$ section of microstrip intervening between the gate terminal and the bisector of the ring. This impedance corresponds to the second resonance from the left in Fig. 2. The bias on the ring was $23 \mathrm{~V}$ and the bias on the microstrip was $0 \mathrm{~V}$. With this biasing scheme there was no need to be concerned with floating the PHEMT voltages with respect to ground since the gate and ring circuit could be directly dc coupled. With the ring resonator circuit connected to the gate of the PHEMT as shown in Fig. 1, the impedance looking into the drain was $-24.9+j 47.7$ or $\Gamma=1.6$. The drain matching circuit shown in Fig. 1 provided a $Z_{L}=$ $8.3-\mathrm{j} 47.7$ as is customarily done to ensure oscillation [12]. The VCO operates below $77 \mathrm{~K}$, near the dielectric constant maximum of the $\mathrm{SrTiO}_{3}$, where the noise figure of the PHEMT and the surface resistance of the Au resonator are minimized. A particular operating temperature of $43 \mathrm{~K}$ was chosen to provide the maximum field induced tunability of the $\mathrm{SrTiO}_{3}$. For testing purposes, both circuits were attached to a brass fixture with conductive epoxy. The fixture was inserted into the vacuum can of a closed-cycle He gas refrigerator equipped with semi-rigid coaxial cables. 


\section{RESULTS AND CONCLUSIONS}

Changing the bias on the ring from 0 to $38 \mathrm{~V}$ varied the oscillator frequency by about $100 \mathrm{MHz}$ around the center frequency. Figure 4(a) shows the spectrum of the oscillator over a very broad bandwidth. No spurs or sub-harmonics were observed. Figure 4(b) shows a typical signal for the $\mathrm{LO}$ at a ring voltage of $38 \mathrm{~V}$. By increasing the ring voltage to $250 \mathrm{~V}$, the tuning range was extended over $500 \mathrm{MHz}$.

In conclusion, a novel tunable microwave ring resonator at $16.7 \mathrm{GHz}$ has been developed. It offers potential advantages over traditional varactor-loaded rings and DROs. To the best of our knowledge, this is the first time that a tunable oscillator based on a thin film ferroelectric structure has been demonstrated at such a high frequency. A successful design approach for such a cryogenic oscillator has been developed. In the near future, the Au ring will be replaced with a $\mathrm{YBa}_{2} \mathrm{Cu}_{3} \mathrm{O}_{7-\delta}$ ring and phase noise measurements will be made to compare performance. The merits of this VCO reside in its high performance potential, small size, simplicity of implementation, MMIC compatibility and its potential for low cost, high volume production.
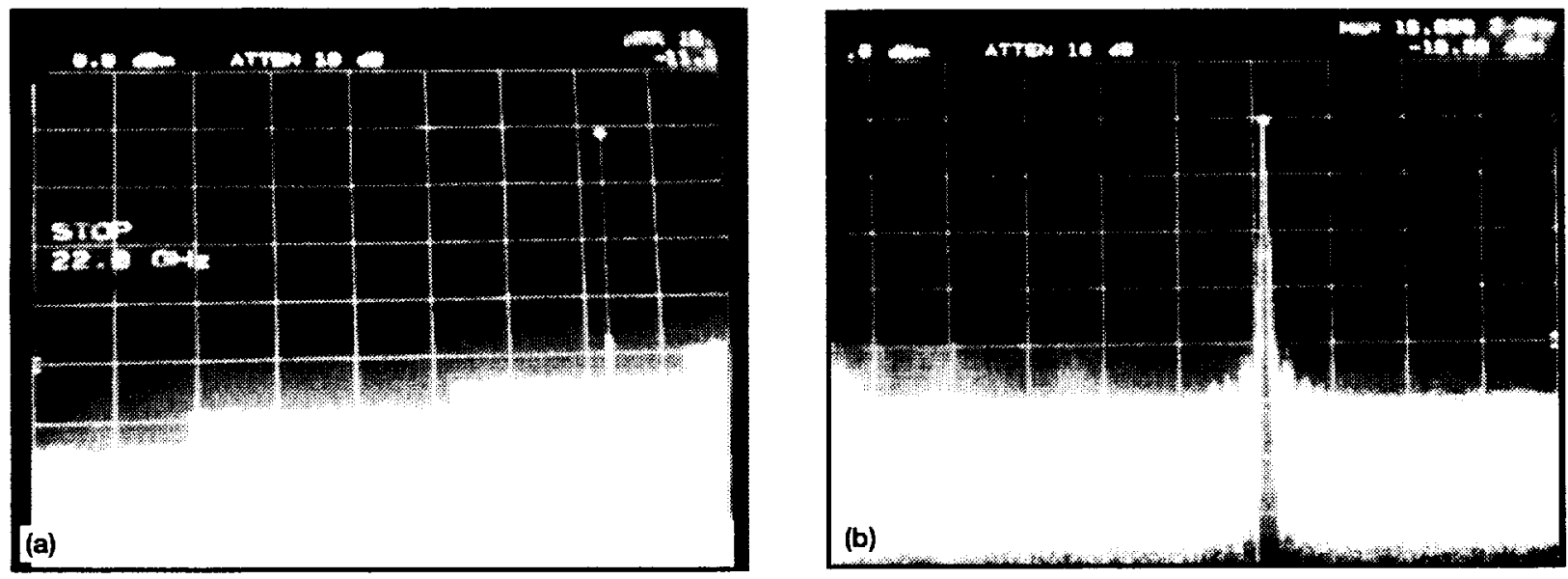

Figure 4.- VCO signals as measured on an HP 8566B Spectrum Analyzer at $43 \mathrm{~K}$ with $V_{d}=2.1 \mathrm{~V}, V_{g}=-0.2 \mathrm{~V}, I_{d}=13.9 \mathrm{~mA}$ and Vring $=38 \mathrm{~V}$. The scale on (a) is 2 to $22 \mathrm{GHz}$, and (b) shows a $500 \mathrm{MHz}$ span with oscillation frequency at $16.696 \mathrm{MHz}$.

\section{References}

[1] J. Portilla, M. de la Fuente, J. Pascual, and E. Artal, IEEE Microwave \& Guided Wave Let., Vol. 7 (1997) pp. 380-382.

[2] K. Kobayashi, L. Tran, A. Oki, et al., IEEE Microwave \& Guided Wave Let., Vol. 5 (1995) pp. 311-312.

[3] J. Lin, Y. Chen, D. Humphrey, et al., IEEE Microwave \& Guided Wave Let., Vol. 5 (1995) pp. 379-381.

[4] A. Khanna, M. Schmidt, and R. Hammond, Microwave Journal, Vol. 34 (1991) pp. 127-130.

[5] O. Llopis, R. Plana, H. Amine, et al., IEEE Trans. Microwave Theory Tech., Vol. 41 (1993) pp. $369-374$.

[6] R. Romanofsky, IEEE Microwave \& Guided Wave Let., Vol. 6 (1996) pp. 286-288.

[7] Y. Wu and F. Rosenbaum, IEEE Trans. Microwave Theory Tech., Vol. 21 (1973) pp. 487-489.

[8] K. Chang, S. Martin, F. Wang, and J. Klein, IEEE Trans. Microwave Theory Tech., Vol. 35 (1987) pp. 1288-1295.

[9] M.J. Dalberth, R.E. Stauber, J.C. Price, C.T. Rogers, and D. Galt, Appl. Phys. Lett., Vol. 72, (1998), pp. 507-509.

[10] F. Van Keuls, R. Romanofsky, D. Bohman, and F. Miranda, "Influence of the Biasing Scheme on the Performance of $\mathrm{Au} / \mathrm{SrTiO}_{3} / \mathrm{LaAlO}_{3}$ Thin Film Conductor/Ferroelectric Tunable Ring Resonators", Presented at the $10^{\text {th }}$ Int'l Symp. Integrated Ferroelectrics, Monterey, CA, Mar. 1-4, 1998.

[11] S. Lu and A. Ferendeci, Electronics. Let., Vol. 30 (1994) pp. 1314-1315.

[12] G. Vendelin, Design of Amplifiers and Oscillators by the S-Parameter Method (John Wiley \& Sons, New York, 1982) pp. 132-182. 
Public reporting burden for this collection of information is estimated to average 1 hour per response, including the time for reviewing instructions, searching existing data sources, gathering and maintaining the data needed, and completing and reviewing the collection of information. Send comments regarding this burden estimate or any other aspect of this collection of information, including suggestions for reducing this burden, to Washington Headquarters Services, Directorate for Information Operations and Reports, 1215 Jefte
Davis Highway, Suite 1204, Arlington, VA 22202-4302, and to the Office of Management and Budget, Paperwork Reduction Project (0704-0188). Washington, DC 20503.
1. AGENCY USE ONLY (Leave blank)
2. REPORT DATE
April 1998
3. REPOAT TYPE AND DATES COVERED
Technical Memorandum

4. TITLE AND SUBTITLE

A Cryogenic GaAs PHEMT/Ferroelectric Ku-Band Tunable Oscillator

6. AUTHOR(S)

Robert R. Romanofsky, Fred W. Van Keuls, and Felix A. Miranda

\section{PERFORMING ORGANIZATION NAME(S) AND ADDAESS(ES)}

National Aeronautics and Space Administration

Lewis Research Center

Cleveland, Ohio 44135-3191

9. SPONSORINGMONITORING AGENCY NAME(S) AND ADDRESS(ES)

National Aeronautics and Space Administration

Washington, DC 20546-0001
WU-632-50-5D-00

5. FUNDING NUMBERS

8. PERFORMING ORGANIZATION REPORT NUMBER

E-11113

10. SPONSORINGMONITORING AGENCY REPORT NUMBER

NASA TM-1998-206967

11. SUPPLEMENTARY NOTES

Prepared for the 3rd European Workshop on Low Temperature Electronics sponsored by the Dipartimento di Fisica, Universita' degli Sturh di Milan and IEEE Electron Devices Society, San Miniato, Tuscany, Italy, June 24-26, 1998. Robert R. Romanofsky and Felix A. Miranda, NASA Lewis Research Center; Fred W. Van Keuls, National Research Council-NASA Research Associate at Lewis Research Center. Responsible person, Robert R. Romanofsky, organization code 5640, (216) 433-3507.

\begin{tabular}{|l|l|} 
12a. OISTRIBUTIONAVAILABILTYY STATEMENT & 12b. DISTRIBUTION CODE
\end{tabular}

Unclassified - Unlimited

Subject Categories: 00 and 00

Distribution: Nonstandard

This publication is available from the NASA Center for AeroSpace Information, (301) $621-0390$

13. ABSTRACT (Maximum 200 words)

A Ku-band tunable oscillator operated at and below $77 \mathrm{~K}$ is described. The oscillator is based on two separate technologies: a $0.25 \mathrm{~mm} \mathrm{GaAs} \mathrm{pseudomorphic} \mathrm{high} \mathrm{electron} \mathrm{mobility} \mathrm{transistor} \mathrm{(PHEMT)} \mathrm{circuit} \mathrm{optimized} \mathrm{for} \mathrm{cryogenic} \mathrm{opera-}$ tion, and a gold microstrip ring resonator patterned on a thin ferroelectric $\left(\mathrm{SrTiO}_{3}\right)$ film which was laser ablated onto a $\mathrm{LaAlO}_{3}$ substrate. A tuning range of up to $3 \%$ of the center frequency was achieved by applying dc bias between the ring resonator and ground plane. To the best of our knowledge, this is the first tunable oscillator based on a thin film ferroelectric structure demonstrated in the microwave frequency range. The design methodology of the oscillator and the performance characteristics of the tunable resonator are described.

14. SUBJECT TERMS

Resonators; Microwave oscillators; Voltage controlled oscillator

15. NUMBER OF PAGES 11

16. PRICE CODE

$\mathrm{A} 03$

\begin{tabular}{|c|c|}
\hline $\begin{array}{c}\text { 17. SECURITY CLASSIFICATION } \\
\text { OF REPORT } \\
\text { Unclassified }\end{array}$ & $\begin{array}{c}\text { 18. SECURITY CLASSIFICATION } \\
\text { OF THIS PAGE } \\
\text { Unclassified }\end{array}$ \\
\hline
\end{tabular}

19. SECURITY CLASSIFICATION OF ABSTRACT Unclassified 